\title{
Clinical malaria and the potential risk of anaemia among preschool-aged children: a population-based study of the 2015-2016 Malawi micronutrient survey
}

\author{
Peter Austin Morton Ntenda ${ }^{1 *}$ (D), Sosten Chilumpha², Edward Tisungane Mwenyenkulu ${ }^{3}$,
} Jane Flora Kazambwe ${ }^{4}$ and Walaa El-Meidany ${ }^{5}$

\begin{abstract}
Background: Anaemia and malaria are common and life-threatening diseases among preschool-aged children in many tropical and subtropical areas, and Malawi is no exception. Accordingly, this study aimed to examine the association of referral clinical malaria with anemia (hemoglobin $[\mathrm{Hb}]<110 \mathrm{~g} / \mathrm{L}$ ) in preschool-aged children in Malawi.

Methods: Using cross-sectional data obtained from the 2015-2016 Malawi Micronutrient Survey (MNS), multivariate logistic regression models were constructed using surveylogistic to account for the complex survey design. Blood samples of 1051 children aged 6-59 months were evaluated for malaria (using rapid diagnostic test [RDT] - SD BIOLINE Malaria Ag P.fPan test histidine-rich protein (HRP-II) ${ }^{\mathrm{TM}}$ ), Hb (using HemoCue 301), a-1-acid glycoprotein (AGP), and serum ferritin biomarkers (using simple sandwich enzyme-linked immunosorbent assay technique, ELISA) and inherited blood disorders from dry blood samples (DBS) using polymerize chain reaction (PCR). Diagnosis of clinical malaria was made on the basis of fever and a positive rapid diagnostic test (RDT).

Results: Of the 1051 PSC analysed, 29\% had anaemia while $24.4 \%$ had a referral to the hospital due to malaria. After adjustments for known confounders, PSC with a history of referral clinical malaria had increased odds of being anaemic (adjusted odds ratio $[\mathrm{aOR}]=4.63,95 \%$ confidence interval [C]: 2.90-7.40), $P<0.0001$.

Conclusions: This study found that clinical malaria increased the risk of anaemia in PSC. Thus, elimination of malariacausing parasites from the PSC's blood should be rapid and complete in order to prevent the progression of uncomplicated malaria to a chronic infection that can lead to the development of malaria-related anaemia.
\end{abstract}

Keywords: Clinical malaria, Anaemia, a-Acid glycoprotein, Serum ferritin, Malawi

\section{Multilingual abstracts}

Please see Additional file 1 for translations of the abstract into the five official working languages of the United Nations.

\section{Background}

According to the World Health Organization (WHO), anaemia is a condition characterized by the reduced number of red blood cells (RBCs) and consequently their

\footnotetext{
*Correspondence: peterantenda@yahoo.com; pntenda@mac.medcol.mw ${ }^{1}$ Malaria Alert Centre, College of Medicine, University of Malawi, Private Bag 360, Chichiri, Blantyre 3, Malawi

Full list of author information is available at the end of the article
}

oxygen-carrying capacity is insufficient to meet the body's physiologic needs [1]. Globally, anaemia is a public health problem with major consequences for human health as well as social and economic development [2]. Anaemia occurs at all stages of the life cycle but it is more pervasive in pregnant women and young children [3]. The global prevalence of anaemia is estimated at $24.8 \%$, while the prevalence of anaemia in preschoolaged children is estimated at $47.4 \%$ [4]. In Malawi, according the 2015-2016 Malawi Demographic and Health Survey (MDHS), 63\% of children suffers from some degree of anaemia [5]. Globally, approximately $50 \%$ of the cases of anaemia are due to iron deficiency (ID), 
although other conditions, such as folate, vitamin B12 and vitamin A deficiencies, chronic inflammation, parasitic infections such as malaria, and inherited disorders can all cause anaemia [6].

Malaria is also a major cause of morbidity and mortality among preschool-aged children in sub-Saharan Africa [7]. It is reported that 219 million new cases of malaria are reported annually, of which a big proportion is children under five years of age [8]. As of 2018, the WHO reported that 435000 deaths owing to malaria had occurred worldwide, of which 403000 deaths (approximately 93\%) were recorded in the sub-Saharan Africa $[9,10]$. Malaria is caused by Plasmodium parasites which are transmitted to people through the bites of infected female Anopheles mosquitoes [11]. In Malawi, through the Ministry of Health's $(\mathrm{MoH})$ National Malaria Control Program, the government has been scaling up the distribution of artemisinin-based combination therapies (ACTs), intermittent preventive treatment for pregnant women (IPTp) using sulfadoxinepyrimethamine (SP), and insecticide-treated nets (ITNs) [12]. This development has led to a decline in under-five mortality from 234 deaths per 1000 live births in the 1990s to 63 deaths per 1000 live births in 2015 [5]. Unfortunately, despite this progress, malaria continues to be the leading cause of death among preschool-aged children in Malawi, accounting for $22 \%$ of all deaths of the under-five children. Furthermore, more than $50 \%$ of all admissions in Malawian hospitals among preschool-aged children are due to malaria [12]. Generally, malaria interventions are reported to reduce the risk of anaemia by $60 \%$ when using a diagnostic cut-off of $80 \mathrm{~g} / \mathrm{L}$ [13].

Malaria parasites constitute one of the most complicated and multifactorial life cycle [14]. The Plasmodium falciparum involves an increased removal of parasitized and unparasitized RBCs through cytokine-mediated dyserythropoiesis and bone marrow suppression to iron delocalization [15]. Precisely, the malaria parasites invade the blood after an infective bite from female Anopheles mosquitoes and end up infecting the RBCs. At the end of that infection cycle, RBCs ruptures and releases more parasites into the bloodstream [16]. As such, this process reduces the number of RBCs resulting in moderate to severe anaemia. A great deal of intervention regarding malaria and anaemia in Malawi have been implemented [17-20] however little has been done to understand why the prevalence anaemia in preschool-aged children remains unacceptably high. Thus, the current study aimed to examine the likelihood of clinical malaria and the development of childhood anaemia in Malawi.

\section{Methods}

\section{Study area}

This study was conducted in Malawi, a sub-Saharan African country located south of the equator. Malawi is bordered by the United Republic of Tanzania, the People's Republic of Mozambique, and the Republic of Zambia. Malawi has a tropical continental climate with maritime influences. Rainfall and temperature vary depending on altitude and proximity to the lake [21]. Malaria transmission is perennial in most areas and peaks during the rainy season from November to April. However, higher malaria transmission occurs along Lake Malawi and the lowland areas of the lower Shire Valley [12].

\section{Data source, and sampling method}

The current study utilized data taken from the 20152016 Malawi Micronutrient Survey (2015-16 MNS) [22]. The MNS was conducted jointly with the 20152016 MDHS between December 2015 and February 2016. The comprehensive methods used in this study can be obtained from the 2015-2016 MNS report. In brief, the 2015-2016 MDHS employed a two-stage sampling designed to produce a nationally representative sample. The first stage selected 850 clusters proportional to population. The second stage selected 27516 households from the clusters with an equal probability systematic selection. The 2015-2016 MNS was selected as a subsample of the MDHS to produce estimates of the key indicators for the country as a whole and stratified by region and residence. A subsample of 105 clusters (35 clusters in each of the three regions) was randomly selected from the 850 MDHS clusters. Figure 1 shows the allocation of selected clusters and households with respect to residence and region.

\section{Data collection and study sample}

Data were collected from women aged 15-49 with children younger than five years of age prior to the survey using standard questionnaires. In the DHS data, of the 25146 eligible households, 24562 were successfully interviewed representing a $98 \%$ response rate. Information on sociodemographic, household and economic factors were collected through face-to-face interviews. As per WHO recommendations, analysis of the current study was restricted to all PSC aged 6-59 months [1].

\section{Field and laboratory procedures}

An axillary temperature of every child was documented where by fever was defined as an axillary temperature of equal to or greater than $37.5^{\circ} \mathrm{C}$. Regarding to laboratory, approximately $7 \mathrm{ml}$ of blood samples were collected from PSC for biochemical and haematological tests. About $5 \mathrm{ml}$ of the blood sample was transferred into trace free elements (Royal Blue Top) test tube and $2 \mathrm{ml}$ into Purple Top - Ethylenediaminetetraacetic acid (EDTA) test tube [22]. About $10 \mu \mathrm{l}$ of whole the blood sample from EDTA vacutainer was used to tested anaemia (Hb concentration) using HemoCue ${ }^{ø} 301$ system 


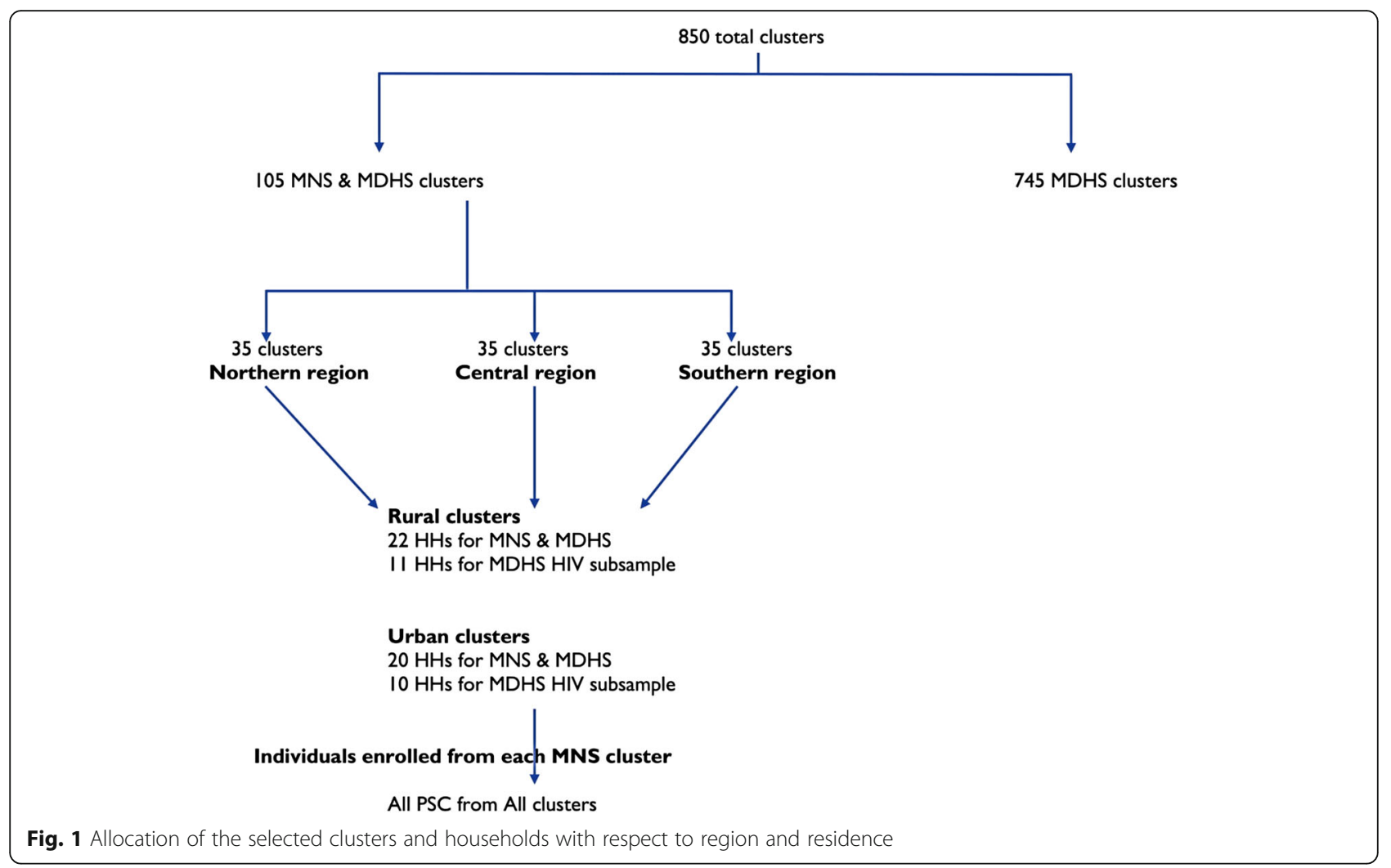

(Ängelholm, Sweden) and another $10 \mu \mathrm{l}$ for malaria using a rapid diagnostic test (RDT) kit the Standard Diagnostic (SD) BIOLINE Malaria Ag P.f/Pan histaminerich protein (HRP-II) ${ }^{\text {Tx }}$ RDT) - Standard Diagnostics Inc., Suwon City, South Korea [23, 24]. The remaining blood from EDTA vacutainer was used to test for RBC folate in women of reproductive age and inherited blood disorders (alpha thalassemia, G6PD, and sickle cell using PCR) in PSC. The plasma from EDTA vacutainer was store at $-20^{\circ} \mathrm{C}$ as back in CHSU laboratory. On the other hand, $100 \mu \mathrm{L}$ of serum from Royal Blue Top was transferred into polymerize chain reaction (PCR) vials and were ship to German for the biochemical examination of Ferritin and Alpha-1-Acid Glycoprotein (AGP) along with other parameters such as Soluble Transferrin Receptor (sTfR), C-reactive protein (CRP), and Retinol Binding Protein (RBP) [22]. A combined measurement of the biochemical tests for ferritin and AGP and other biochemical micronutrient parameters were performed using an inexpensive, sensitive, and simple sandwich enzyme-linked immunosorbent assay (ELISA) technique in the VitMin laboratories in German [25]. To identify the glucose-6-phosphate dehydrogenase (G6PD) deficiency, the widely known G6PD A - variant was investigated using three commercially available TaqMan probe sets (Applied Biosystems Foster City, CA, USA); A376G (rs1050829) distinguished A and B isoforms, G202A (rs1050828) identified the A - variant, and sex was scored using SRY_VIC and ABCD1_CCHSOH-FAM for $\mathrm{Y}$ and $\mathrm{X}$ chromosomes, respectively. Each assay included positive and negative controls, with random sample duplicates [6]. To detect alpha-thalassemia trait, the 3.7-kb $\alpha$-globin gene deletion $\left(-\alpha^{3.7}\right)$ was rated using a copynumber variant TaqMan assay with custom TaqMan probes, as described elsewhere [26]. The procedure for the identification of sickle status has been described before [6]. In brief, amplification of the $\beta$-globin gene was performed using forward (5'-TGC TTA CCA AGC TGT GAT TCC-3') and reverse (5'-CTT CCT ATG ACA TGA ACT TAA CCA-3') primers. Haemoglobin $S$ (HbS) mutation (Glu6Val) was evaluated by a custom TaqMan probe (RT-PCR) designed for the HbS (sickle, rs334) polymorphism.

\section{Measures \\ Dependent variable}

Childhood anaemia was the dependent variable of this study. Using the WHO recommendations, anaemia in PSC was characterized as children with $\mathrm{Hb}$ concentration $<110 \mathrm{~g} / \mathrm{L}$ after adjusting for altitude [1]. Altitudeadjusted $\mathrm{Hb}$ concentration less than $40 \mathrm{~g} / \mathrm{L}$ or greater than $180 \mathrm{~g} / \mathrm{L}$ were considered extreme and excluded from the analysis [27]. 


\section{Main independent variable}

Clinical malaria was the main independent variable assessed in this study. Clinical malaria was defined as any PSC with malaria-related symptoms such as fever an axillary temperature $\geq 37.5^{\circ} \mathrm{C}$, chills, severe malaise, headache or vomiting at the time of examination or $48 \mathrm{~h}$ prior to the examination in the presence of a Plasmodium falciparum positive blood smear [28]. However, in this study, a positive Plasmodium falciparum result was confirmed using the RDT [22].

\section{Covariates}

The covariates included in this study were; age of the child in months, sex of the child, and fever in last two weeks, malaria test result, $\alpha-1$-acid glycoprotein (AGP), serum ferritin, $\alpha$-thalassemia, household hunger scale, type of place of residence, and region of residence were used as covariates. The sex was grouped as (male/female), the age of the children was categorized as 6-11, $12-23,24-35,36-47$, and $48-59$ months. As regards fever in the last two weeks, the respondents were asked if the child had a fever (yes/no) in the last two weeks, while malaria test result was categorized as positive or negative. AGP and serum ferritin were grouped as normal or abnormal. Abnormal value for AGP was AGP levels of greater than $1 \mathrm{~g} / \mathrm{L}$ and abnormal levels for serum ferritin were less than $12 \mu \mathrm{g} / \mathrm{L}$. Serum ferritin adjusted for inflammation using internal regression approach [29]. The household hunger scale was categorized as little to no hunger and moderate to severe hunger using the recommendations from the Food and Nutrition Technical Assistance III Project (FANTA) [30]. The type of place of residence (rural and urban), and region of residence (northern, central, and southern) were used to assessed area of residence and region respectively.

\section{Statistical analysis}

All statistical analyses were conducted using SAS software version 9.4 (SAS Institute, Cary, NC, USA). To account for the complex survey design, the survey-specific SAS procedures for weighting, clustering, and stratification in the survey design (SurveyFreq) was used to report the basic statistics. Baseline characteristics were reported as weighted frequency and percentages. The $P$ values from the bivariate analyses were reported using Rao-Scott Chi-Square to test the differences between groups anaemic (yes/no). All factors that showed significance at $P \leq 0.25$ in the bivariable analyses were fitted into the final models of the regression analyses in order to have the best fit statistical model. The multivariate regression analyses were performed using Surveylogistic where anaemia was the dependent variable and characteristics such as sociodemographic, clinical, biochemical, and inherited blood disorders were the independent variables. Adjusted odds ratio $(\mathrm{aOR})$ with their $p$-values and 95\% confidence interval $(C I)$ were reported.

\section{Ethical statement}

Protocols for the MNS 2016 were approved by the National Health Sciences Research Committee (NHSRC) and the Institutional Review Board (IRB) of ICF Macro (https://dhsprogram.com/What-We-Do/Protecting-thePrivacy-of-DHS-Survey-Respondents.cfm). The survey was implemented by the National Statistics Office (NSO) and the Community Health Sciences Unit (CHSU). At the beginning of each interview and prior to blood collection, informed consent from MNS eligible households and the survey participants were sought. Furthermore, community leaders provided the consent of survey activities. ICF Macro IRB ensures that the survey is in line with the U.S. Department of Health and Human Services regulations for the protection of human subjects (45 CFR 46), while the NHSRC ensures that the survey was conducted with laws and norms of the Malawi.

\section{Results}

Baseline characteristics of the study participants

Of the $1051 \mathrm{PSC}, 29.0 \%$ had anaemia $(\mathrm{Hb}<110 \mathrm{~g} / \mathrm{L})$. The prevalence of clinical malaria was $27.4 \%$. Similarly, the prevalence of Plasmodium falciparum positive RDT was $27.6 \%$. The prevalence of fever in the last two weeks was 43.3\%. Table 1 reports the baseline characteristics of the study sample. Approximately, $51 \%$ of the children were male and a majority of children (56\%) had abnormal levels of $\alpha-1$-acid glycoprotein while about $22 \%$ had abnormal levels of serum ferritin. Furthermore, a majority of children did not have G6PD (72\%) nor $\alpha$-thalassemia (60\%). A majority of children (60\%) were residing in household with moderate to severe hunger and more than threequarter (89\%) of the children were rural dwellers.

\section{Results of the bivariate analysis}

Table 2 presents the prevalence of anaemia by clinical and demographic characteristics of study sample. The prevalence of anaemia was significantly high in PSC of age group $6-11$ months $(P<0.0001)-$ Fig. 2 presents the prevalence of anaemia by age of the child. The prevalence of anaemia was also high in children with a history of fever in the last two weeks $(P<0.0001)$, in PSC with a positive RDT $(P<0.0001)$, in PSC with referral clinical malaria $(P<0.0001)$. Furthermore, the prevalence of anaemia was high in PSC with abnormal levels of AGP $(P<0.0001)$ and serum ferritin $(P<0.0001)$. 
Table 1 Sociodemographic, comorbidities and biochemical characteristics of the study sample

\begin{tabular}{lll}
\hline Variable & $\begin{array}{l}\text { Frequency } \\
n=1051\end{array}$ & $\begin{array}{l}\text { Percent } \\
(\%)\end{array}$ \\
\hline Sex & & \\
Female & 539 & 49.18 \\
Male & 512 & 50.82
\end{tabular}

\section{Age (months)}

6-11

97

12-23

24-35

36-47

48-59

Fever in last 2 weeks

Yes

Malaria test result ${ }^{\dagger}$

Positive

Negative

Clinical malaria ${ }^{a}$

Yes

No

Alpha1-Acid Glycoprotein

Normal

Abnormal

Serum ferritin ${ }^{b}$

Normal

Abnormal

G6PD $(n=1004)$

Unaffected

Affected

Carrier

Alpha-thalassemia $(n=999)$

Unaffected

Affected

Carrier

Household hunger scale

Little to none

Moderate to severe

Type of place of residence

$$
\text { Urban }
$$

Rural

Region of residence

North

Central

Southern

Outcome variable
Table 1 Sociodemographic, comorbidities and biochemical characteristics of the study sample (Continued)

\begin{tabular}{lll}
\hline Variable & $\begin{array}{l}\text { Frequency } \\
n=1051\end{array}$ & $\begin{array}{l}\text { Percent } \\
(\%)\end{array}$ \\
\hline Any anemia & & \\
$<110 \mathrm{~g} / \mathrm{L}$ & 742 & 70.96 \\
$\geq 110 \mathrm{~g} / \mathrm{L}$ & 309 & 29.04 \\
\hline
\end{tabular}

G6PD Glucose-6-phosphate dehydrogenase

${ }^{a}$ Defined as an individual with malaria-related symptoms (fever [axillary temperature $\geq 37.5^{\circ} \mathrm{C}$, chills, severe malaise, headache or vomiting) at the time of examination or 1-2 days prior to the examination in the presence of a

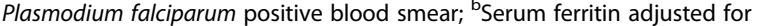
inflammation using internal regression approach, ${ }^{+}$malaria test using a rapid diagnostic test (RDT) kit the Standard Diagnostic (SD) BIOLINE Malaria Ag P.f/

Pan histamine-rich protein (HRP-II) ${ }^{T M}$ RDT)

\section{Multivariable results of clinical malaria and anaemia}

Table 3 shows unadjusted and adjusted odds ratio of clinical malaria on anemia. PSC who had a history of referral clinical malaria, were over four times $(\mathrm{aOR}=$ 4.63; 95 CI: 2.90-7.40); $P<0.0001$, compared to those PSC without a history of clinical malaria even after adjusting for known factors associated with anaemia. Additionally, the odds of anaemia were high in PSC of the age group 6-11 months (aOR $=4.40 ; 95 \%$ $C I$ : $1.82-10.61) ; P=0.0003$, in PSC with a history of fever in the last two weeks $(\mathrm{aOR}=1.58$; 95\% CI: $1.04-$ 2.39); $P=0.0324$, in children with high levels of AGP $(\mathrm{aOR}=2.13 ; 95 \% \mathrm{CI}: 1.36-3.34) ; P=0.0010$, those with iron deficiency $(\mathrm{aOR}=2.37 ; 95 \% C I$ : 1.40-4.02); $P=$ 0.0014 , and those with alpha-thalassemia disease $(\mathrm{aOR}=4.08 ; 95 \%$ CI: 1.74-9.59); $P=0.0004$.

\section{Discussion}

The aim of this study was to examine the likelihood of clinical malaria and the development of childhood anaemia in Malawi. This is the first study to report the association of clinical malaria and the likelihood of anaemia in PSC using a nationally representative sample in Malawi. Accordingly, this study revealed that children who had clinical malaria were more likely to develop anaemia.

Anaemia occurs when RBCs are destroyed at an increased rate than the rate at which are supposed to be replaced or when $\mathrm{RBC}$ production falls below the rate at which the body requires to maintain a steady state [31]. The pathogenesis of malarialanaemia is said to be multifactorial but the exact mechanisms behind several haematology changes in the course of malaria is poorly understood [32]. However, this process involves a great deal of phenomenon including immune and non-immune mediated destruction of the parasitized and nonparasitized RBCs (pRBC's and npRBC's), bone 
Table 2 Sociodemographic, comorbidities and biochemical characteristics by anemia ${ }^{a}$

\begin{tabular}{|c|c|c|c|}
\hline Variable & $\begin{array}{l}\text { Non-anemic } \\
n(\%)\end{array}$ & $\begin{array}{l}\text { Anemic }^{a} \\
n(\%)\end{array}$ & $P$ value \\
\hline Sex & & & 0.5618 \\
\hline Female & $374(69.39)$ & $165(30.61)$ & \\
\hline Male & $368(71.88)$ & $144(28.13)$ & \\
\hline Age (months) & & & $<0.0001$ \\
\hline $6-11$ & $45(46.39)$ & $52(53.61)$ & \\
\hline $12-23$ & $136(61.54)$ & $85(38.46)$ & \\
\hline $24-35$ & $185(71.98)$ & $72(28.02)$ & \\
\hline $36-47$ & $202(76.52)$ & $62(23.48)$ & \\
\hline $48-59$ & $174(82.08)$ & $38(17.92)$ & \\
\hline Fever in last 2 weeks & & & $<0.0001$ \\
\hline Yes & $320(63.37)$ & $185(36.63)$ & \\
\hline No & $422(77.29)$ & $124(22.71)$ & \\
\hline Malaria test result ${ }^{\dagger}$ & & & $<0.0001$ \\
\hline Positive & $127(45.68)$ & $151(54.32)$ & \\
\hline Negative & $615(79.56)$ & $158(20.44)$ & \\
\hline Clinical malaria $^{\mathrm{b}}$ & & & $<0.0001$ \\
\hline Yes & $123(45.39)$ & $148(54.61)$ & \\
\hline No & $619(79.36)$ & $161(20.64)$ & \\
\hline Alpha1-Acid Glycoprotein & & & $<0.0001$ \\
\hline Normal & $366(82.62)$ & $77(17.38)$ & \\
\hline Abnormal & $376(61.84)$ & $232(38.16)$ & \\
\hline Serum ferritin ${ }^{c}$ & & & $<0.0001$ \\
\hline Normal & $613(73.41)$ & $222(26.59)$ & \\
\hline Abnormal & $129(59.72)$ & $87(40.28)$ & \\
\hline G6PD & & & 3.0684 \\
\hline Unaffected & $514(71.09)$ & $209(28.91)$ & \\
\hline Affected & $82(68.91)$ & 37 (31.09) & \\
\hline Carrier & $116(71.60)$ & $46(28.40)$ & \\
\hline Alpha-thalassemia & & & $<0.0001$ \\
\hline Unaffected & $445(73.07)$ & $164(26.93)$ & \\
\hline Affected & $39(48.75)$ & $41(51.25)$ & \\
\hline Carrier & $223(71.94)$ & $87(28.06)$ & \\
\hline Household hunger scale & & & 0.3706 \\
\hline Little to none & $349(71.96)$ & $136(28.04)$ & \\
\hline Moderate to severe & $393(69.43)$ & $173(30.57)$ & \\
\hline Type of place of residence & & & 0.1684 \\
\hline Urban & $89(76.07)$ & $28(23.93)$ & \\
\hline Rural & $653(69.91)$ & $281(30.09)$ & \\
\hline Region of residence & & & 0.6143 \\
\hline North & $257(69.09)$ & $115(30.91)$ & \\
\hline Central & $277(72.32)$ & $106(27.68)$ & \\
\hline Southern & $208(70.27)$ & $88(29.73)$ & \\
\hline
\end{tabular}

G6PD Glucose-6-phosphate dehydrogenase

${ }^{\mathrm{a}} \mathrm{Hb}<110 \mathrm{~g} / \mathrm{L}$; defined as an individual with malaria-related symptoms (fever [axillary temperature $\geq 37.5^{\circ} \mathrm{C}$, chills, severe malaise, headache or vomiting) at the time of examination or 1-2 days prior to the examination in the presence of a Plasmodium falciparum positive blood smear; ${ }^{~ C}$ Serum ferritin adjusted for inflammation using internal regression approach, ${ }^{\dagger}$ malaria test using a rapid diagnostic test (RDT) kit the Standard Diagnostic (SD) BIOLINE Malaria Ag P.f/ Pan histamine-rich protein (HRP-II) $\left.{ }^{\mathrm{TM}} \mathrm{RDT}\right)$ marrow impairment, altered cytokine balance, nutritional deficiency, and interactions with common hemoglobinopathies and erythrocyte defects and thalassemia which compromises rapid recovery from anaemia - Fig. 3 presence the pathogenesis of malaria infection and anemia [33, 34].

Malarial infection begins when sporozoites are inoculated together with anti-coagulant saliva in the course of a blood meal of an infected Anopheles mosquito [16, 35, 36]. Following inoculation of the sporozoites, the parasites travel to the liver in search of a conducive environment in the hepatocyte and successfully replicate in the liver, after which newly formed merozoites are released back in the bloodstream [16, 37]. During the blood stage of the asexual developmental cycle, malaria parasites replicate inside RBCs. As this process continues more RBCs get destroyed and merozoites induce changes in RBC membranes and increase splenic activities hence increase destruction and clearance of parasitized RBCs [38].

Infection with Plasmodium species induce homeostatic imbalance and lower $\mathrm{Hb}$ concentration thus resulting in anemia [34]. It has been reported that imbalance of cytokines such as tumor necrosis factor alpha (TNF- $\alpha$ ), interleukin-6 (IL-6), IL-10 and interferon gamma (IFN- $\gamma$ ) resulting from malaria related-inflammation can induce changes in iron absorption and distribution (iron delocalization) [39]. Iron delocalization end up in decreasing the release of iron from the reticuloendothelial system as well as increasing uptake of iron from the reticuloendothelial system thus resulting in iron accumulation in tissues/secretions and iron deficiency in blood [39, 40]. Generally, hepcidin, an iron regulatory hormone is a crucial determinant in the relationship between inflammation and anaemia. It is known that pro-inflammatory cytokines secretion is up-regulated by hepcidin from macrophages and hepatocytes which in turn inhibits iron absorption and its release from macrophages by down-regulating the concentration of ferroportin thereby contributing to iron deficiency anaemia through the reduction of RBCs production [41].

Another pathway by which an altered cytokines balance and inflammation can induce anemia is through bone marrow depression (dyserythropoiesis) and erythrophagocytosis following low IL-10 and IL12 or excess of $\mathrm{T}$ helper cell type 1 (th1), cytokines follicular helper $\mathrm{T}$ cells (TFH), TNF- $\alpha$ and nitric acid (NO) [42]. Often times, dyserythropoiesis induces the morphological abnormalities of the erythroid series which include multinuclearity of the normoblasts, intracytoplasmic bridging, karyorrhexis, 


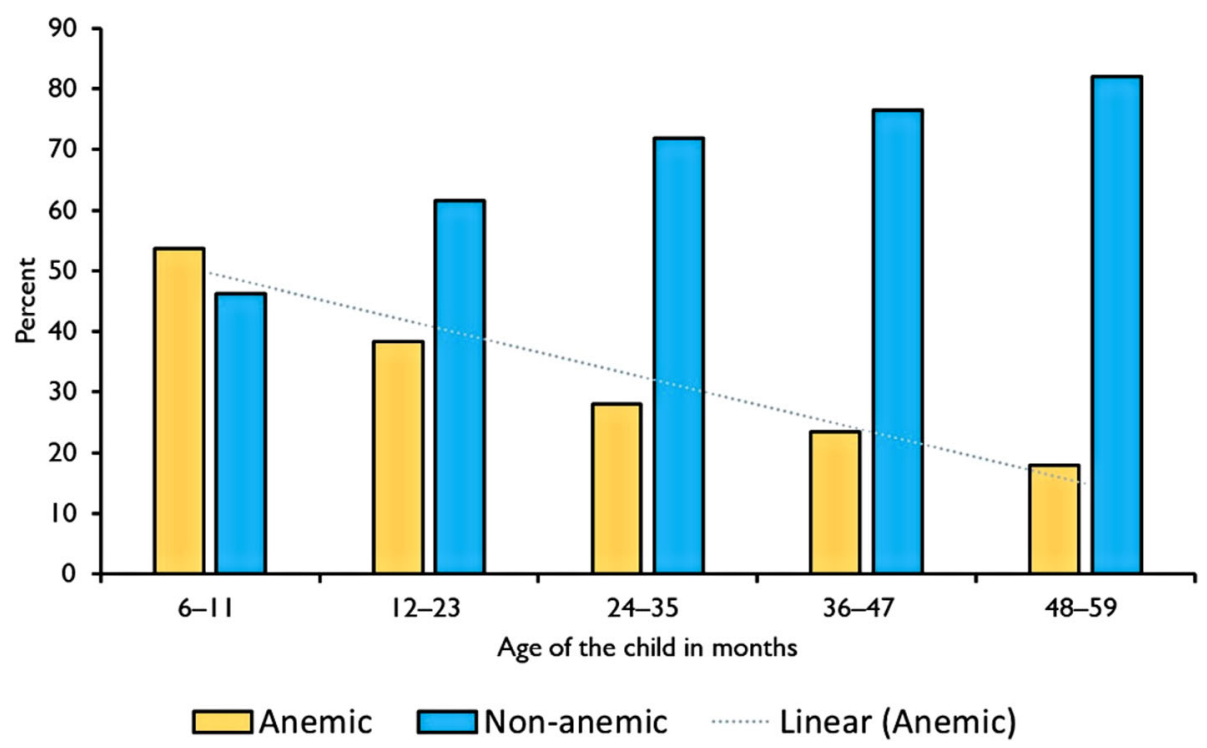

Fig. 2 Prevalence of anaemia by the age of the child

incomplete and unequal mitotic nuclear divisions in RBCs of the individuals infected with malaria [4345], hence induces erythrophagocytosis of the parasitized and unparasitized RBCs activities. Additionally, the mechanism that leads to reduced production of RBCs may be due to erythroid hypoplasia induced by inflammation [46]. The normal response to erythropoietin is suppressed due to an autologous serum factor. This may further suppress the growth of early precursors of RBCs including the burst forming unit- erythroid (BFU-E) and colony forming-unit erythroid (CFU-E) [47, 48]. Furthermore, another pathway by which malarial infection increases erythrophagocytosis of the parasitized and unparasitized RBCs is through activation of complement and deposition of immune complexes on RBCs by cytotoxic natural killer and natural killer cells [49-51]. It has been reported that complement plays a role in the occurrence of anemia in the course of malaria infection by opsonization of unparasitized RBCs with C3 fragments which in turn can lead to phagocytosis of RBCs [52, 53].

In addition to clinical malaria, the other characteristics such as the age of the child, a history of fever in the last two weeks, AGP, serum ferritin, and alpha thalassemia were significantly associated with anaemia in PSC. The results of age are in line with the past research where it was reported that anaemia is frequent among children around the time of the growth spurt, especially between the ages of
6 and 24 months $[54,55]$. During the infant growth spurt (6-12 months), the physical development is rapid, and the blood volume is largely expanded, whereas the iron storage from the maternal source has usually been depleted. Therefore, an inadequate intake of exogenous iron during this period could lead to anaemia [56]. Fever is a common response that occurs as the result of infection and inflammatory diseases and it goes beyond the site of infection [57]. It is known that some pathogens can end up in the production of pyrogens, chemicals that efficiently modify the thermostat status of the hypothalamus to raise body temperature and cause fever [58]. Generally, pyrogens may induce the leukocytes to release endogenous pyrogens such as interleukin1 (IL-1), IL-6, interferon- $\gamma$ (IFN- $\gamma$ ), and tumour necrosis factor (TNF) [58, 59]. In turn, these molecules can then trigger the release of prostaglandin E2 (PGE2) from other cells, resetting the hypothalamus to initiate fever $[58,59]$. We also found that children with alpha-thalassemia had increased odds of being anaemic. Alpha-thalassemia is inherited as an autosomal recessive disorder which is characterized by a microcytic hypochromic mild anaemia and a clinical phenotype varying from almost asymptomatic to lethal haemolytic anaemia [60]. Furthermore, children with abnormal levels of serum ferritin and AGP levels were significantly more likely to be anaemic. AGP is a measure of chronical inflammation while serum ferritin is a measure of iron deficiency. The mechanisms through which both of these 
Table 3 Association of clinical malaria and anemia $^{\mathrm{a}}$ in preschool-aged children

\begin{tabular}{|c|c|c|c|c|c|c|}
\hline Variable & $\operatorname{crOR}(C)$ & & $P$ value & $\mathrm{aOR}(\mathrm{Cl})$ & & $P$ value \\
\hline \multicolumn{7}{|c|}{ Clinical malaria $^{\mathrm{b}}$} \\
\hline Yes & 3.78 & $(2.55-5.59)$ & $<0.0001$ & 4.63 & $(2.90-7.40)$ & $<0.0001$ \\
\hline No & 1.00 & & & 1.00 & & \\
\hline \multicolumn{7}{|l|}{ Age (months) } \\
\hline $6-11$ & 4.87 & $(2.39-9.93)$ & $<0.0001$ & 4.40 & $(1.82-10.61)$ & 0.0003 \\
\hline $12-23$ & 2.66 & $(1.46-4.86)$ & 0.0399 & 2.18 & $(1.05-4.56)$ & 0.1179 \\
\hline $24-35$ & 1.29 & $(0.73-2.30)$ & 0.0450 & 0.90 & $(0.44-1.88)$ & 0.0071 \\
\hline $36-47$ & 1.20 & $(0.67-2.16)$ & 0.0186 & 1.11 & $(0.56-2.21)$ & 0.0733 \\
\hline $48-59$ & 1.00 & & & 1.00 & & \\
\hline \multicolumn{7}{|c|}{ Fever in last 2 weeks } \\
\hline Yes & 1.75 & $(1.21-2.53)$ & 0.0029 & 1.58 & $(1.04-2.39)$ & 0.0324 \\
\hline No & 1.00 & & & 1.00 & & \\
\hline \multicolumn{7}{|c|}{ Alpha1-Acid Glycoprotein } \\
\hline Abnormal & 2.50 & $(1.64-3.81)$ & $<0.0001$ & 2.13 & $(1.36-3.34)$ & 0.0010 \\
\hline Normal & 1.00 & & & 1.00 & & \\
\hline \multicolumn{7}{|l|}{ Serum ferritin ${ }^{c}$} \\
\hline Abnormal & 1.97 & $(1.26-3.09)$ & 0.0031 & 2.37 & $(1.40-4.02)$ & 0.0014 \\
\hline Normal & 1.00 & & & 1.00 & & \\
\hline \multicolumn{7}{|c|}{ Alpha-thalassemia } \\
\hline Unaffected & 1.01 & $(0.66-1.53)$ & 0.0030 & 0.90 & $(0.57-1.42)$ & 0.0018 \\
\hline Affected & 3.62 & $(1.84-7.10)$ & $<0.0001$ & 4.08 & $(1.74-9.59)$ & 0.0004 \\
\hline Carrier & 1.00 & & & 1.00 & & \\
\hline \multicolumn{7}{|c|}{ Type of place of residence } \\
\hline Urban & 1.27 & $(0.53-3.01)$ & 0.5981 & 2.17 & $(0.97-4.89)$ & 0.0601 \\
\hline Rural & 1.00 & & & 1.00 & & \\
\hline
\end{tabular}

parameters result in anaemia have been explained earlier in this paper and elsewhere [61].

\section{Strengths and limitations}

The findings can be generalized in the Malawian context due to the use of the nationally representative sample. The use of malaria RDTs was helpful since they can assist in making a rapid, accurate diagnosis in circumstances where the microscopy-based diagnosis may be unreliable or available. The use of serum ferritin and alpha-thalassemia makes our results on clinical malaria to be robust and valid. However, the use of crosssectional study design cannot provide a causal relationship between the explanatory variable and anaemia. The HemoCue system was used for assessment of $\mathrm{Hb}$ levels. Additional studies may need the use of other $\mathrm{Hb}$ indices to define anaemia. The RDT may not be able to detect some infections with lower numbers of malaria parasites circulating in the patient's bloodstream. In addition, all positive RDTs should be followed by microscopy.

\section{Conclusion}

In this study we aimed to examine the likelihood of clinical malaria and the development of anaemia among PSC in Malawi. Indeed, the results of this study have demonstrated that clinical malaria is a potential risk factor for anaemia in PSC. Thus, clearance of the Plasmodium parasite from the PSC's blood should be rapid and complete in order to prevent progression of uncomplicated malaria to a chronic infection that leads to malaria-related anaemia. The results of this study have some policy implications, i.e. programmes that aim at combating anaemia in infants and young children 


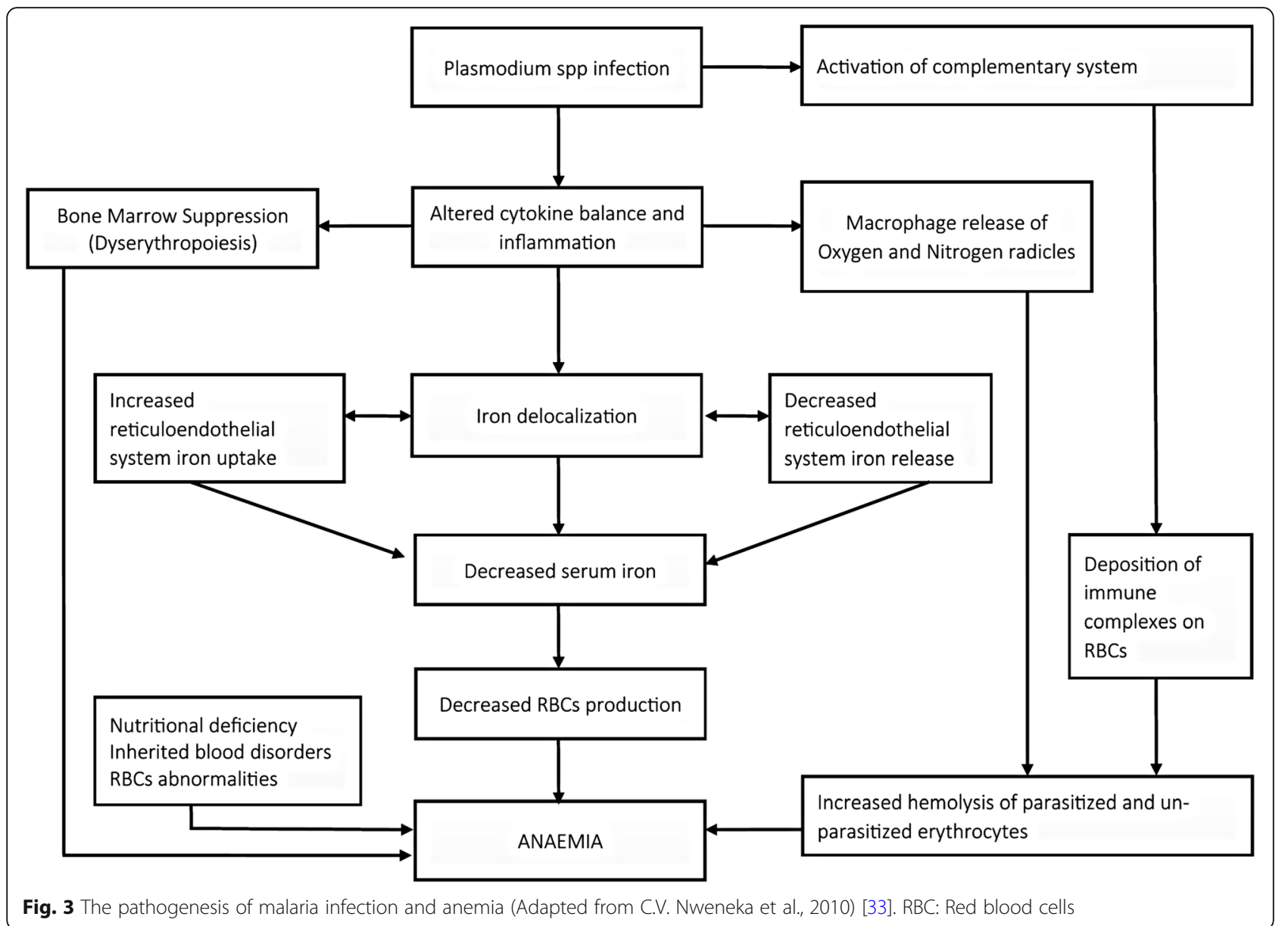

should not focus on iron supplementation, deworming treatment, and complementary feeding practices as strategies to manage anemia, diagnosis and case management of malaria should also be considered promptly as it has been proved by this study that clinical malaria is associated with anaemia in PSC thus, posing threats to the strategies that were out in place to tackle anaemia in Malawi.

\section{Supplementary information}

Supplementary information accompanies this paper at https://doi.org/10. 1186/s40249-019-0607-8.

Additional file 1: Multilingual abstracts in the five official working languages of the United Nations.

\section{Abbreviations}

AGP: Alpha-1-acid glycoprotein; AOR: Adjusted odds ratio; CDC: Center for Disease Control; CFR: Code of Federal Regulations; CHSU: Community Health Sciences Unit; Cl: Confidence interval; CRP: C-reactive protein;

EDTA: Ethylenediaminetetraacetic acid; ELISA: Enzyme-linked immunosorbent assay; Fer: Ferritin; g/dL: grams per deciliter; Hb: Hemoglobin; HIV: Human immunodeficiency virus; ID: Iron deficiency; IL: Interleukin; INF: Interferon; IRB: Institutional Review Board; MDHS: Malawi Demographic and Health Survey; MNS: Malawi Micronutrient Survey; MPHC: Malawi Population and Housing Census; NHSRC: National Health Sciences Research Committee;
NC: New York; NSO: National Statistical Office; aOR: Adjusted odds ratio; PCR: Polymerase chain reaction; PGE: Prostaglandin E; PSC: Preschool children; RBCs: Red blood cells; RBP: Retinol Binding Protein; RDTs: Rapid Diagnostic Test; SAS: Statistical analysis software; SEAs: Enumeration areas; STfR: Soluble Transferrin Receptor; TNF: Tumor necrosis factor; USA: United States of America; VIF: Inflation factor; WHO: World Health Organization

\section{Acknowledgements}

The author is sincerely grateful to the MEASURE DHS for the provision of the population-based dataset for this analysis through their archives; https:// dhsprogram.com/data/

\section{Author' contributions}

All authors contributed to the conception and design of the study. P.A.M.N. acquired data, conducted analysis and interpreted the results. P.A.M.N., J.F.K, and E.T.M., drafted the first article. S.C. and W.E. revised the draft critically for important intellectual content. All authors reviewed and approved the final version of the manuscript.

\section{Funding}

The author did not receive any funding to conduct this study.

\section{Availability of data and materials}

The datasets generated and/or analysed during the current study are available in the MEASURE DHS repository; https://dhsprogram.com/data/

\section{Ethics approval and consent to participate}

To ensure that the 2015-16 MDHS and MNS were conducted in line with the principles of ethics in order to void the risk of harming the study participants, a joint proposal was submitted and approved by the National 
Health Sciences Research Committee (NHSRC), the Institutional Review Board (IRB) of ICF Macro, and the Centers for Disease Control (CDC) in Atlanta. Informed consent for the survey took place at several levels involving seeking an informed consent from community leaders, MNS eligible households and the survey participants. ICF IRB ensured that the survey complied with the U.S. Department of Health and Human Services regulations for the protection of human subjects (45 CFR 46), while the NHSRC ensured that the survey was conducted in line with Malawian laws and norms.

\section{Consent for publication}

Not Applicable.

\section{Competing interests}

The authors declare that they have no competing interests.

\section{Author details}

${ }^{1}$ Malaria Alert Centre, College of Medicine, University of Malawi, Private Bag 360, Chichiri, Blantyre 3, Malawi. 'Ministry of Health and Population, Department of Planning and Policy Development, PO Box 30377, Lilongwe, Malawi. ${ }^{3}$ The Malawi University of Science and Technology, P.O Box 5196, Limbe, Malawi. ${ }^{4}$ NBS Bank PLC, Head Office NBS House Corner Chipembere Highway \& Johnstone Roads Ginnery Corner Blantyre, P.O. Box 32251, Chichiri, Blantyre 3, Malawi. ${ }^{5}$ Department of Nutrition, High Institute of Public Health, Alexandria University, Hiph 65 El-Horreya Avenue. El-Ibrahimia, Alexandria, Egypt.

Received: 24 June 2019 Accepted: 11 November 2019 Published online: 25 November 2019

\section{References}

1. World Health Organization (WHO). Haemoglobin concentrations for the diagnosis of anaemia and assessment of severity. Geneva: World Health Organization; 2011.

2. WHO/CDC. Worldwide prevalence of anaemia 1993-2005: WHO Global Database on Anaemia. Geneva: Switz WHO Press; 2005. p. 51.

3. Bekele A, Tilahun M, Mekuria A. Prevalence of anemia and its associated factors among pregnant women attending antenatal care in health institutions of Arba Minch town, Gamo Gofa zone, Ethiopia: A Crosssectional study. Anemia. 2016;2016.

4. World Health Organization (WHO). Global anaemia prevalence and number of individuals affected. Vitamin and Mineral Nutrition Information System (VMNIS).2015. Geneva, Switz. http://www.who.int/ vmnis/anaemia/prevalence/summary/anaemia_data_status_t2/en/. Accessed 15 August 2017.

5. National Statistical Office (NSO) [Malawi] and ICF. Malawi Demographic and Health Survey 2015-16. Zomba, Malawi, and Rockville, Maryland: NSO and ICF; 2017.

6. McGann PT, Williams AM, Ellis G, McElhinney KE, Romano L, Woodall J, et al. Prevalence of inherited blood disorders and associations with malaria and anemia in Malawian children. Blood advances. 2018;2:3035-44.

7. World Health Organization (WHO). Children: Reducing Mortality. Geneva, Switz 2018. https://www.who.int/news-room/fact-sheets/detail/childrenreducing-mortality. Accessed May 11, 2019.

8. World Health Organization (WHO). Malaria. Geneva, Switz. 2019. https:// www.who.int/malaria. Accessed September 12, 2019.

9. World Health Organization (WHO). Malaria, Key Facts. Geneva, Switz 2019. https://www.who.int/news-room/fact-sheets/detail/malaria. Accessed June 20, 2019

10. World Health Organization (WHO). Global Health Observatory data; number of malaria deaths. Geneva, Switz. 2018. https://www.who.int/gho/malaria/ epidemic/deaths/en/ Acccessed July 5, 2019.

11. World Health Organization (WHO). Malaria. Geneva, Switz. 2015. https:// www.afro.who.int/health-topics/malari. Accessed May 11, 2019.

12. USAID and CDC. The President's Malaria Initiative. Fighting Malaria and Saving Lives. US Pres Malar Initiat. 2018.

13. National Malaria Control Programme (NMCP) and ICF. Malawi Malaria Indicator Survey 2017. Lilongwe, Malawi, and Rockville, Maryland: NMCP and ICF; 2018.
14. Sumbele IUN, Sama SO, Kimbi HK, Taiwe GS. Malaria, moderate to severe anaemia, and malarial anaemia in children at presentation to hospital in the Mount Cameroon area: a cross-sectional study. Anemia. 2016;2016.

15. Castelli F, Sulis F, Caligaris S. The relationship between anaemia and malaria: apparently simple, yet controversial. Trans R Soc Trop Med Hyg. 2014;108:181-2.

16. Centers for Disease Control and Prevention (CDC). Malaria Biology. US Dep Heal Hum Serv. 2018. https://www.cdc.gov/malaria/about/biology/index. html. Accessed August 5, 2019.

17. Mathanga DP, Walker ED, Wilson ML, Ali D, Taylor TE, Laufer MK. Malaria control in Malawi: current status and directions for the future. Acta Trop. 2012;121:212-7.

18. Malenga T, Kabaghe AN, Manda-Taylor L, Kadama A, McCann RS, Phiri KS, et al. Malaria control in rural Malawi: implementing peer health education for behaviour change. Global Health. 2017:13:84.

19. Kabaghe AN, Chipeta MG, McCann RS, Terlouw DJ, Tizifa T, Truwah Z, et al. Access and adequate utilization of malaria control interventions in rural Malawi: a descriptive quantitative study. Malar J. 2018;17:104.

20. National Statistical Office (NSO), Macro International Inc. Malawi Demographic and Health Survey 1992. Zomba, Malawi, and Macro International Inc. Calverton: NSO and Macro International Inc.; 1994

21. National Statistical Office N, ICF Macro. Malawi Demographic and Health Survey 2010. Zomba, Malawi, and Calverton, Maryland, USA: NSO and ICF Macro. Malawi: 2011

22. National Statistical Office (NSO), Community Health Sciences Unit (CHSU) [Malawi], Centers for Disease Control and Prevention (CDC), and University Emory. Malawi Micronutrient Survey 2015-16. Atlanta GA, USA NSO, CHSU, CDC Univ Emory. 2017.

23. HemoCue ${ }^{\oplus} \mathrm{Hb} 301$ System. Accurate POC Anemia Screening From the Pioneers. SE-262 23 Ängelholm, Sweden 2015. https://www.hemocue. com/-/media/hemocue-images/hemocuedotcom-images/product-images/ hb/pdf-folders-etc/web-update-01092015.pdf. Accessed May 9, 2019.

24. Obeagu El, Chijioke UO, Ekelozie IS. Malaria Rapid Diagnostic Test (RDTs). Ann Clin Lab Res. 2019:06:10-2.

25. Erhardt JG, Estes JE, Pfeiffer CM, Biesalski HK, Craft NE. Combined Measurement of Ferritin, Soluble Transferrin Receptor, Retinol Binding Protein, and C-Reactive Protein by an Inexpensive, Sensitive, and Simple Sandwich Enzyme-Linked Immunosorbent Assay Technique. 2004;134 (11): 3127-32.

26. Grimholt RM, Urdal P, Klingenberg O, Piehler AP. Rapid and reliable detection of a-globin copy number variations by quantitative real-time PCR. BMC Hematol. 2014;14:4.

27. Sullivan KM, Mei Z, Grummer-Strawn L, Parvanta I. Haemoglobin adjustments to define anaemia. Trop Med Int Heal. 2008;13:1267-71.

28. Mutanda AL, Cheruiyot P, Hodges JS, Ayodo G, Odero W, John CC. Sensitivity of fever for diagnosis of clinical malaria in a Kenyan area of unstable, low malaria transmission. Malar J. 2014;13:163.

29. Namaste SM, Rohner F, Huang J, Bhushan NL, Flores-Ayala R, Kupka R, et al. Adjusting ferritin concentrations for inflammation: Biomarkers Reflecting Inflammation and Nutritional Determinants of Anemia (BRINDA) project. Am I Clin Nutr. 2017;106(suppl_1):359S-71S.

30. Ballard T, Coates J, Swindale A, Deitchler M. Household hunger scale: indicator definition and measurement guide. 2011. Washington: Food Nutr Tech Assist II Proj FHl; 2016. p. 360.

31. Marcel EC. Anemia. In: Walker H, Hall W, Hurst J, editors. Clinical Methods: The History, Physical, and Laboratory Examinations. Chapter 147. 3rd ed. Boston: Butterworths; 1990

32. Kai OK, Roberts DJ. The pathophysiology of malarial anaemia: where have all the red cells gone? BMC Med. 2008;6:24.

33. White NJ. Anaemia and malaria. Malar J. 2018;17:371.

34. Nweneka CV, Doherty CP, Cox S, Prentice A. Iron delocalisation in the pathogenesis of malarial anaemia. Trans R Soc Trop Med Hyg. 2010;104: 175-84.

35. Hopp CS, Sinnis $P$. The innate and adaptive response to mosquito saliva and Plasmodium sporozoites in the skin. Ann N Y Acad Sci. 2015; 1342:37-43.

36. Antinori S, Galimberti L, Milazzo L, Corbellino M. Biology of human malaria plasmodia including Plasmodium knowlesi. Mediterr J Hematol Infect Dis. 2012;4:-e2012013.

37. Yamauchi LM, Coppi A, Snounou G, Sinnis P. Plasmodium sporozoites trickle out of the injection site. Cell Microbiol. 2007;9:1215-22. 
38. Deng X, Duffy SP, Myrand-Lapierre M-E, Matthews K, Santoso AT, Du Y-L, et al. Reduced deformability of parasitized red blood cells as a biomarker for anti-malarial drug efficacy. Malar J. 2015;14:428.

39. Paesano R, Natalizi T, Berlutti F, Valenti P. Body iron delocalization: the serious drawback in iron disorders in both developing and developed countries. Pathog Glob Health. 2012;106:200-16.

40. Wilson NO, Bythwood T, Solomon W, Jolly P, Yatich N, Jiang Y, et al. Elevated levels of IL-10 and G-CSF associated with asymptomatic malaria in pregnant women. Infect Dis Obstet Gynecol. 2010;2010.

41. Gonçalves RM, Lima NF, Ferreira MU. Parasite virulence, co-infections and cytokine balance in malaria. Pathog Glob Health. 2014;108:173-8.

42. Jongen-Lavrencic M, Peeters HRM, Wognum A, Vreugdenhil G, Breedveld FC, Swaak AJG. Elevated levels of inflammatory cytokines in bone marrow of patients with rheumatoid arthritis and anemia of chronic disease. J Rheumatol. 1997:24(8):1504-9.

43. Bupathi M, Tiu RV, Maciejewski JP. Myelodysplastic/myeloproliferative neoplasms. In: Myelodysplastic Syndr. Second Ed; 2013.

44. Castro-Gomes T, Mourão LC, Melo GC, Monteiro WM, Lacerda MVG, Braga ÉM. Potential immune mechanisms associated with anemia in Plasmodium vivax malaria: a puzzling question. Infect Immun. 2014;82:3990-4000.

45. Heimpel H, Kellermann K, Neuschwander N, Högel J, Schwarz K. The morphological diagnosis of congenital dyserythropoietic anemia: results of a quantitative analysis of peripheral blood and bone marrow cells. Haematologica. 2010;95:1034-6.

46. Straat $M$, van Bruggen $R$, de Korte $D$, Juffermans NP. Red blood cell clearance in inflammation. Transfus Med Hemother. 2012;39:353-61.

47. Elliott S, Sinclair AM. The effect of erythropoietin on normal and neoplastic cells. Biologics. 2012;6:163-89

48. Leowattana W, Krudsood S, Tangpukdee N, Brittenham G, Looareesuwan S. Defective erythropoietin production and reticulocyte response in acute Plasmodium falciparum malaria-associated anemia. Southeast Asian J Trop Med Public Health. 2008;39:581-8.

49. Waitumbi JN, Opollo MO, Muga RO, Misore AO, Stoute JA. Red cell surface changes and erythrophagocytosis in children with severe plasmodium falciparum anemia. Blood. 2000;95:1481-6

50. Autino B, Corbett Y, Castelli F, Taramelli D. Pathogenesis of malaria in tissues and blood. Mediterr J Hematol Infect Dis. 2012;4:-e2012061.

51. Belachew EB. Immune response and evasion mechanisms of Plasmodium falciparum parasites. J Immunol Res. 2018;2018:6529681.

52. Stoute JA. Role of Complement in Severe Malarial Anemia. In: Stoute J. (eds) Complement Activation in Malaria Immunity and Pathogenesis. Cham: Springer; 2018. https://doi.org/10.1007/978-3-319-77258-5_3

53. Biryukov S, Stoute JA. Complement activation in malaria: friend or foe? Trends Mol Med. 2014;20(5):293-301.

54. Ntenda PAM, Chuang K-Y, Tiruneh FN, Chuang Y-C. Multilevel analysis of the effects of individual- and community-level factors on childhood Anemia, severe Anemia, and hemoglobin concentration in Malawi. J Trop Pediatr. 2017:64:267-78.

55. Ntenda PAM, Nkoka O, Bass P, Senghore T. Maternal anemia is a potential risk factor for anemia in children aged 6-59 months in southern Africa: a multilevel analysis. BMC Public Health. 2018;18:650.

56. Zhao A, Zhang Y, Peng Y, Li J, Yang T, Liu Z, et al. Prevalence of Anemia and its risk factors among children 6-36 months Old in Burma. Am J Trop Med Hyg. 2012;87:306-11.

57. InformedHealth.org [Internet]. Cologne G 2006-. What is an inflammation? Inst Qual Effic Heal Care 2010. https://www.ncbi.nlm.nih.gov/books/NBK2792 98/. Accessed May 28, 2018.

58. Iumen. Innate Nonspecific Host Defenses - Inflammation and Fever 2019. https://courses.lumenlearning.com/microbiology/chapter/inflammation-andfever/. Accessed March 19, 2019.

59. Dinarello CA, Cannon JG, Mancilla J, Bishai I, Lees J, Coceani F. Interleukin-6 as an endogenous pyrogen: induction of prostaglandin E2 in brain but not in peripheral blood mononuclear cells. Brain Res. 1991;562:199-206.

60. Harteveld CL, Higgs DR, Petrou M, Brugiatelli M, Old J, Hurley P, et al. AlphaThalassaemia. Orphanet J Rare Dis. 2010;5:13.

61. Nairz M, Theurl I, Wolf D, Weiss $G$. Iron deficiency or anemia of inflammation? : Differential diagnosis and mechanisms of anemia of inflammation TT - Eisenmangel oder Entzündungsanämie? : Differenzialdiagnose und Mechanismen der Entzündungsanämie. Wien Med Wochenschr. 2016:166:411-23.

\section{Ready to submit your research? Choose BMC and benefit from:}

- fast, convenient online submission

- thorough peer review by experienced researchers in your field

- rapid publication on acceptance

- support for research data, including large and complex data types

- gold Open Access which fosters wider collaboration and increased citations

- maximum visibility for your research: over $100 \mathrm{M}$ website views per year

At BMC, research is always in progress.

Learn more biomedcentral.com/submissions 